\title{
Influence of the patch loading length on the buckling coefficient of longitudinally stiffened plate girders
}

\author{
Influencia de la longitud de carga concentrada sobre el coeficiente de pandeo de vigas \\ esbeltas rigidizadas longitudinalmente
}

\author{
Nelson Loaiza (1) ', Carlos Graciano (1D) ', Rolando Chacón (10)2 \\ ${ }^{1}$ Facultad de Minas, Universidad Nacional de Colombia (Sede Medellín). Calle 59A \# 63-20. C. P. 050034. Medellín, Colombia. \\ ${ }^{2}$ Departament d'Enginyeria Civil i Ambiental, Universitat Politècnica de Catalunya. Calle Jordi Girona, 1-3. C. P. 08034. Barcelona, España.
}

\author{
ARTICLE INF0: \\ Received: November 16, \\ 2018 \\ Accepted: March 22, 2019
}

\section{AVAILABLE ONLINE:}

March 29, 2019

\section{KEYWORDS:}

Finite element analysis, patch loading, longitudinal stiffeners, buckling coefficient, plate girders

Análisis por elementos finitos, carga concentrada, rigidizadores

longitudinales, coeficiente de pandeo, vigas esbeltas
ABSTRACT: Currently, one of the most used steel bridge assembly methods is the Incremental Launching Method (ILM). Its practical application consists in passing the bridge assembly through a launching shoe as well as over each support pile. For steel plate girders, a concentrate vertical reaction also known as patch loading is generated over one the flanges when ILM is employed, and depending on the geometrical and material properties of the girder, buckling failure in the web panel may occur. To overcome this type of failure, plate girders are reinforced with longitudinal stiffeners. Therefore, this paper aims at investigating the effect of the bearing length on the elastic buckling behavior of longitudinally stiffened girder webs subjected to patch loading. Buckling coefficients of longitudinally stiffened girder webs are calculated by means of linear finite element analysis. Furthermore, a parametric analysis is performed to study the influence of other geometric parameters such as the panel aspect ratio and the geometrical properties of the longitudinal stiffener on the buckling coefficient. The results show that for longitudinally stiffened girder webs the buckling coefficient increases with the loading length. However, this conclusion is considerably affected by other factors such as the position of the stiffener, and panel aspect ratios.

RESUMEN: Uno de los métodos de ensamblaje de puentes de acero más utilizados en la actualidad es el Método de Lanzamiento por Empujes Sucesivos, también abreviado como ILM por sus siglas en ingles. Su aplicación práctica consiste en pasar el ensamblaje de puentes a través de las zapatas de lanzamiento, así como sobre cada pila de soporte. Para vigas de acero se genera una reacción vertical de carga concentrada sobre una de las aletas cuando se emplea ILM, y dependiendo de las propiedades geométricas y de material de la viga esto puede ocasionar una falla de pandeo localizado sobre el alma. Para evitar este tipo de fallas, las vigas son reforzadas con rigidizadores longitudinales. Muchas investigaciones han estudiado la influencia de diferentes parámetros geométricos sobre el comportamiento de pandeo elástico de vigas sujetas a carga concentrada, sin embargo, el efecto de la longitud de apoyo ha recibido poca atención. Este artículo se enfoca en investigar la influencia de la longitud de apoyo en el comportamiento de pandeo elástico de vigas esbeltas con rigidización longitudinal sujetas a carga concentrada. El coeficiente de pandeo de las vigas esbeltas rigidizadas longitudinalmente fue calculado por medio análisis lineal por elementos finitos. Para ello se realizó un estudio paramétrico con el propósito de evaluar la influencia de otras variables adicionales como la relación de aspecto del panel y las propiedades geométricas de los rigidizadores sobre el coeficiente de pandeo. Los resultados muestran que para una viga rigidizada longitudinalmente el coeficiente de pandeo incrementa con la longitud de carga. Sin embargo, este incremento se ve considerablemente afectado por otros factores tales como la posición del rigidizador y la relación de aspecto del panel.

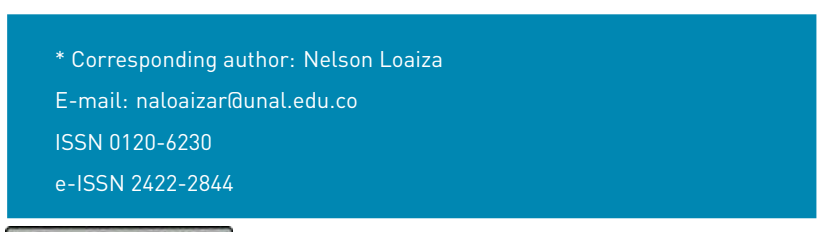




\section{Notation}

$\begin{array}{ll}a & \begin{array}{l}\text { length of web panel } \\ b_{f}\end{array} \\ b_{s t} & \text { width of flange } \\ b_{1} & \text { width of stiffener } \\ D & \text { position of longitudinal stiffener } \\ & {\left[=E t_{w}^{3} / 12\left(1-v^{2}\right)\right]} \\ E & \text { Young's modulus } \\ F_{c r} & \text { critical buckling load } \\ F_{U} & \text { Ultimate loads } \\ F_{y} & \text { Yielding load according to the Eurocode } \\ & \text { EC3-Part. 1-5 }\end{array}$

$h_{w} \quad$ depth of web panel

$I_{s t} \quad$ effective second moment of area of stiffener

$k_{F} \quad$ buckling coefficient

$k_{f l} \quad$ buckling coefficient for longitudinally stiffened plate girders

$k_{s l} \quad$ contribution of a longitudinal stiffener to the buckling coefficient $k_{f} l$

$s_{s} \quad$ length of patch load or stiff bearing length

$t_{f} \quad$ flange thickness

$t_{s t} \quad$ stiffener thickness

$t_{w} \quad$ web thickness

$\beta \quad$ flange stiffness parameter $\left[=b_{f} t_{f}^{3} / h_{w} t_{w}^{3}\right]$

$\gamma_{s} \quad$ relative flexural rigidity of the longitudinal stiffener $\left[=E I_{x t} / D h_{v}\right]$

$\gamma^{t} \quad$ transition rigidity

$\mathcal{V} \quad$ Poisson's ratio

\section{Introduction}

A proper determination of the patch loading resistance of steel plate girders is a typical structural verification that requires attention in steel bridges erected by launching. Occasionally, slender I-girders with considerable web height are used as structural alternatives. These thin-walled webs are frequently reinforced with longitudinal stiffeners to increase bending and shear strengths, and for bridge erected by incremental launching these stiffeners also provide an enhancement for patch loading resistance. Patch loading may generate a localized failure in the web plates in the form of an intertwined mechanism of yielding and buckling often referred to as web folding or web crippling. For the sake of predicting ultimate load capacities of steel plate girders subjected to concentrated loading, researchers have separated the theoretical studies for elastic buckling load $F_{c r}$ and for the ultimate load $F_{U}$. Ultimate load capacities can be defined by calibrating instability-related resistance functions $\chi=f(\lambda)$, where the slenderness parameter $\lambda=f\left(F_{c r}, F_{y}\right)$ or by using closed form solutions $F_{U}$ as upper bounds. The former verification procedure is implemented in European provisions [1] whereas the latter is implemented in American provisions [2].

Several studies in the literature have been devoted to investigate cases where the load is fractionally applied over the girder flanges. In particular, for the calculation of $F_{c r}$, the elastic buckling analysis of both unstiffened and longitudinally stiffened girder webs is a theoretically complex problem due to the large number and range of geometrical parameters involved. Initially, studies on the linear buckling behavior of simply supported plates under compressive loading have been conducted [3-5]. It has been demonstrated that the critical buckling load of simply supported plates increases with the use of longitudinal stiffeners placed adequately [6, 7]. Additionally, results using the folded plate theory have shown that a stiffener placed at one-fifth of the girder depth increases considerably the critical load for patch loading [8]. The contribution of flanges on the buckling coefficients for patch loading was also investigated [9].

Later on, an extensive numerical investigation led to the inclusion of the positive effect of longitudinal stiffening into the formulation for buckling coefficients of longitudinally stiffened webs under patch loads [10]. Moreover, numerical analyses have been performed to investigate the rotational restraints provided to the web plates by the flanges in unstiffened webs, developing new formulae for crane girders [11]. A linear buckling analysis was carried out to describe the behavior of unstiffened plates under interacting patch loading and bending moment [12]. Recently, a series of numerical studies were conducted to investigate the elastic buckling of unstiffened and stiffened panels subjected to opposite patch loading for different boundary conditions [13]. Furthermore, factorial design analysis was also employed to examine the influence of several geometric parameters on the buckling coefficient of longitudinal stiffened girder webs [14].

The results from the studies mentioned above can be summarized as follows, the influence of several geometric parameters has been investigated such as: (a) panel 

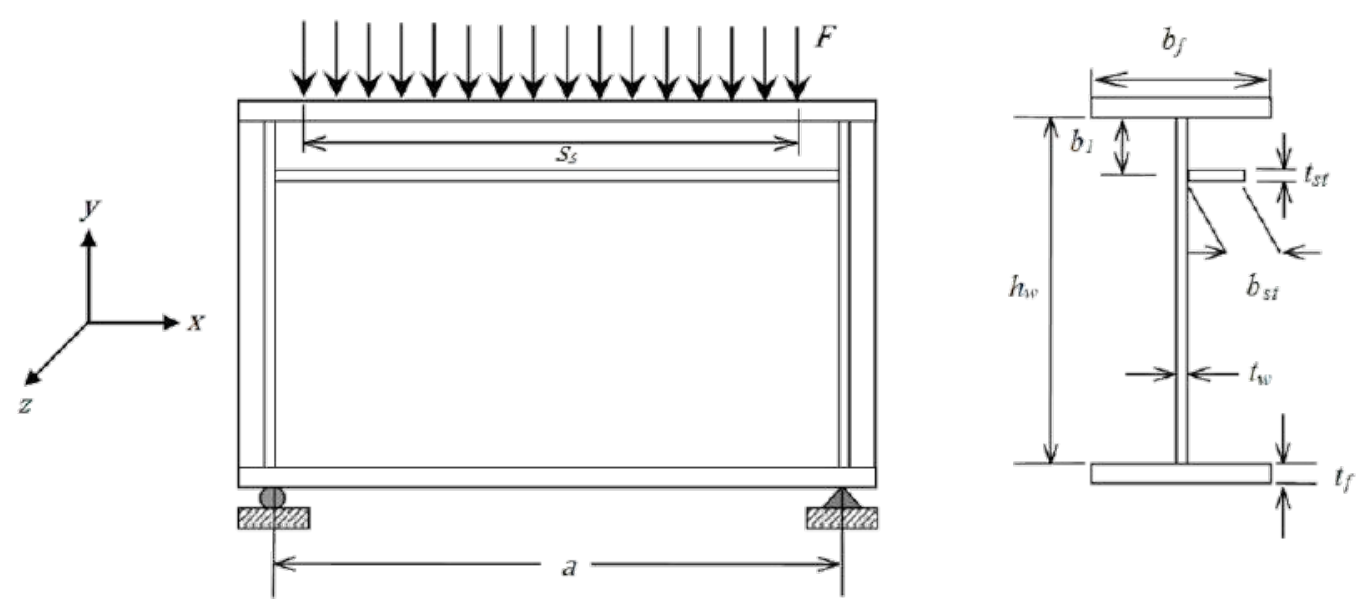

Figure 1 Longitudinally stiffened plate girder subjected to continuous loading (see notation)

aspect ratio; (b) flange stiffness parameter; (c) size of the longitudinal stiffener; and (d) relative position of the stiffener. However, there are still some uncovered issues as for instance, in the patch loading case the available formulae were developed for short loading lengths [15-17]. Some works related to this influence have been presented for ultimate load capacities rather than for elastic critical buckling loads [18-24]. Therefore, this paper aims at investigating the influence of the loading length on the buckling coefficients and transition rigidity for longitudinally stiffened girders subjected to patch loading. Buckling coefficients are computed numerically by means of linear finite element analysis; the patch loading length is varied to cover cases with large loading. These analyses are also conducted for various panel aspect ratios, stiffener positions, and stiffener rigidities. The results show that the buckling coefficient increases with increasing load lengths for certain aspect ratios. Aspect ratios and stiffener rigidities shape these observations to a major extent as described in the following.

\section{Numerical model}

Figure 1 shows the nomenclature used herein for a longitudinally stiffened girder subjected to patch loading. According to the classical buckling theory [25-27], the critical buckling load $F_{c r}$ of a plate is expressed as displayed in Equation (1):

$$
F_{c r}=k_{F} \frac{\pi^{2} E t_{W}^{3}}{12\left(1-v^{2}\right) h_{w}}
$$

where $k_{F}$ is the buckling coefficient that depends on edge support conditions, on stress type and on the panel aspect ratio of the plate element.
For simplicity, a parameter commonly used to describe the capacity of a stiffener to resist buckling is the flexural rigidity $\left(\gamma_{s}\right)$ of the stiffener, which can be expressed relative to the plate stiffness as shown in Equation (2)

$$
\gamma_{s}=\frac{E I_{s t}}{h_{w} D}
$$

where $D=E t_{w}{ }^{3} / 12\left(1-\nu^{2}\right)$ is the flexural rigidity of a unit width of the web plate. The second moment of area $I_{s t}$ of the longitudinal stiffener is calculated with respect to its centroidal axis parallel to the web plate, for an effective cross section consisting of the stiffener itself and an effective portion of the web plate having a width of $15 t_{w}$ on each side of the stiffener weld [1].

Buckling coefficients are computed herein through eigenvalue analysis using the FE-program ANSYS [28]. Shell elements $S 181$ from the ANSYS element library [28] were used to model the web, flanges (top and bottom) and the longitudinal stiffener. Due to the symmetry in geometry, loading and boundary conditions only one-half of the girder was modeled. Transverse stiffeners at the end of the girder were replaced with kinematic constraints, i.e., displacements in $\mathrm{y}$ and $z$ directions, and rotation in $x$ direction were restricted. To model the symmetry, displacement in the $x$ direction, and rotation in $\mathrm{y}$ and $z$ directions were restrained (Figure 1). A patch load was applied by loading all the nodes located in the loaded flange along a loading length equal to $s_{s} / 2$, displacements in the $x$ and $z$ directions, and all rotations were restricted, allowing only vertical displacement in the $\gamma$ direction (following the hypothesis of a stiff bearing length $s_{s}$ ).

For simplicity, a rectangular cross section of the stiffener (flat stiffener) is used in the parametric analysis. The 
following geometry is used as a basis for the analysis: $h_{w}=$ $1000 \mathrm{~mm}, a=1000 \mathrm{~mm}, t_{w}=4 \mathrm{~mm}, t_{f}=8 \mathrm{~mm}, b_{f}=250 \mathrm{~mm}$, $b_{1}=200 \mathrm{~mm}, s_{s}=200 \mathrm{~mm}, t_{s t}=3 \mathrm{~mm}$. Figure 2 shows the adopted finite element mesh with 4872 elements after performing a convergence study (see Figure 3). Additionally, the buckling coefficients are calculated using a Young's modulus $E=210 \mathrm{GPa}$ and Poisson's ratio $\nu$ $=0.3$. Table 1 shows a comparison between buckling coefficients computed with the numerical model and those obtained numerically in [10]. It is worth noticing that the buckling coefficients in Table 1 were obtained for a fixed loading length $\left(s_{s} / h_{w}=0.2\right)$. A very good agreement is observed for a panel aspect ratio $a / h_{w}=1.0$ with greater but acceptable differences for $a / h_{w}=2.0$ and $a / h_{w}=4.0$.

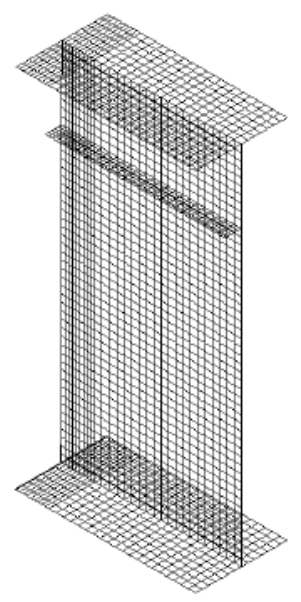

Figure 2 Finite element mesh of a longitudinal stiffened plate girder

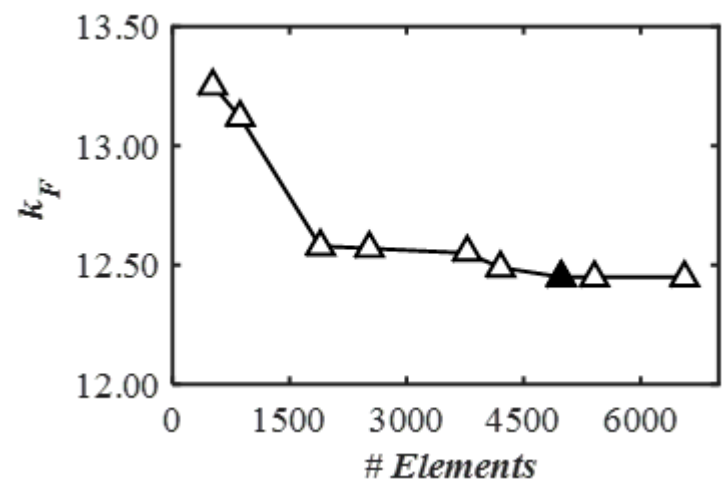

Figure 3 Convergence of the finite element mesh

\section{Parametric study}

In the literature, several investigations $[10,11,13,14]$ on buckling coefficients for longitudinally stiffened girder
Table 1 Comparison of $k_{F}$ computed using FEM with those obtained in [10]

\begin{tabular}{ccccc}
\hline$a / h_{w}$ & $\gamma_{s}$ & $k_{F}$ & $k_{F}[10]$ & $k_{F} / k_{F}[10]$ \\
\hline 1 & 0 & 8.61 & 8.50 & 1.01 \\
& 14.8 & 12.45 & 12.43 & 1.00 \\
& 40.4 & 12.98 & 12.95 & 1.00 \\
& 86.2 & 13.23 & 13.22 & 1.00 \\
& 158.1 & 13.50 & 13.49 & 1.00 \\
& 406.6 & 14.23 & 14.19 & 1.00 \\
\hline 2 & 0 & 6.76 & 6.80 & 0.99 \\
& 14.8 & 7.43 & 7.44 & 1.00 \\
& 40.4 & 8.42 & 8.36 & 1.01 \\
& 86.2 & 9.71 & 9.52 & 1.02 \\
& 158.1 & 10.80 & 10.42 & 1.04 \\
& 406.6 & 12.07 & 11.38 & 1.06 \\
\hline 4 & 0 & 6.96 & 6.59 & 1.06 \\
& 14.8 & 6.90 & 6.87 & 1.00 \\
& 40.4 & 7.18 & 7.09 & 1.01 \\
& 86.2 & 7.52 & 7.34 & 1.02 \\
& 158.1 & 8.01 & 7.64 & 1.05 \\
& 406.6 & 9.43 & 8.56 & 1.10 \\
\hline
\end{tabular}

webs have focused their attention on the influence of the panel aspect ratio $\left(a / h_{w}\right)$, relative position of the stiffener $\left(b_{1} / h_{w}\right)$, relative flexural rigidity of the stiffener $\left(\gamma_{s}\right)$, and the load length-to-panel height ratio $\left(s_{s} / h_{w}\right)$. Nevertheless, in most cases the girder height $\left(h_{w}\right)$ has been kept constant while the panel width is increased (a), which leads to the consideration of short loading lengths. Therefore, in order to investigate the influence of the loading length as a more refined parameter, the stiff bearing length-to-panel width ratio $\left(s_{s} / a\right)$ was used herein.

In this section, a parametric analysis is conducted in order to evaluate the influence of the following parameters:

- Patch loading length was varied $s_{s} / a$ : $[0.1,0.2,0.3$, $0.4,0.5,0.6]$.

- Relative position of the stiffener $b_{1} / h_{w}=[0.1,0.2,0.3]$.

- Relative flexural rigidity of the stiffener $\gamma_{s}=[0,14.8$, $40.4,86.2,158.1,406.6]$, corresponding to six values of stiffeners thickness $t_{s t}=[0,3,4,5,6,8] \mathrm{mm}$.

- Panel aspect ratio $a / h_{w}=[1,2,4]$.

It is worth mentioning that for the sake of minimizing the influence of the torsional rigidity of the longitudinal stiffener in the studied phenomenon, the width-to-thickness ratio was fixed to $b_{s t} / t_{s t}=15$. 
Figures 3 to 5 present the buckling coefficients computed for various panel aspect ratios $a / h_{w}$ and loading lengths $s_{s} / a$, the relationship between the buckling coefficients and the relative flexural rigidity of the stiffeners may be clearly observed. Moreover, the buckling coefficient of longitudinally stiffened girder webs subjected to a fixed patch loading length $\left(s_{s} / h_{w}=0.2\right)$ presented in [10], is calculated using the following expressions:

$$
\begin{gathered}
k_{F}=5.82+2.1\left(\frac{h_{w}}{a}\right)^{2}+0.46 \sqrt[4]{\frac{b_{f} t_{f}^{3}}{h_{w} t_{w}^{3}}}+k_{s l} \\
k_{s l}=\left(5.44 \frac{b_{1}}{a}-0.21\right) \sqrt{\gamma_{s}} \\
\gamma_{s} \leq \gamma^{t}=14\left(\frac{a}{h_{w}}\right)^{2.9}+211\left(0.3-\frac{b_{1}}{a}\right)
\end{gathered}
$$

As can be noticed in Equations (3) to (5), the contribution of the stiffener to the critical load depends on the parameter ratio $b_{1} / a$, valid within the range of $0.039 \leq b_{1} / a \leq 0.3$ [29]. In the particular case of $a / h_{w}=4$ and $b_{1} / h_{w}=0.1$ $\left(b_{1} / a=0.025\right)$ the contribution of the stiffener $\left(k_{s l}\right)$ to the critical load was not considered.

\section{Results}

\subsection{Influence of the bearing length $s_{s} / a$}

Figures 4 to 6 show the results for the buckling coefficients $k_{F}$ in terms of the relative flexural rigidity of the stiffener $\gamma_{s}$ for various loading lengths $s_{s} / a$, and the stiffener positions $b_{1} / h_{w}=0.1,0.2$ and 0.3 . It is clearly observed that the buckling coefficients $k_{F}$ exhibit a bilinear behavior, where $k_{F}$ varies almost linearly for small values of $\gamma_{s}$, until reaching a value in which the slope decreases significantly. The corresponding value of $\gamma_{s}$ at which the slope changes is called the transition rigidity $\gamma^{t}$ [10]. These results are similar to those obtained previously in $[10,13]$.

Figure 4 shows the buckling coefficient $k_{F}$ computed in terms of the relative flexural rigidity $\gamma_{s}$ for various loading lengths $s_{s} / a$, with a panel aspect ratio $a / h_{w}=1$. Meanwhile, Figure 5 displays the corresponding values for $a / h_{w}=2$. In both cases, the buckling coefficients increase proportionally with the relative position of the stiffener for aspect ratios $a / h_{w}=1$ and 2 , and a maximum value for the buckling coefficient is achieved when stiffener is placed at $b_{1} / h_{w}=0.3$. Conversely, Figure 6 shows the results for $a / h_{w}=4$ in which however, the buckling coefficient remains rather constant with respect to the stiffener position. In all cases, the buckling coefficients increase with the bearing length.

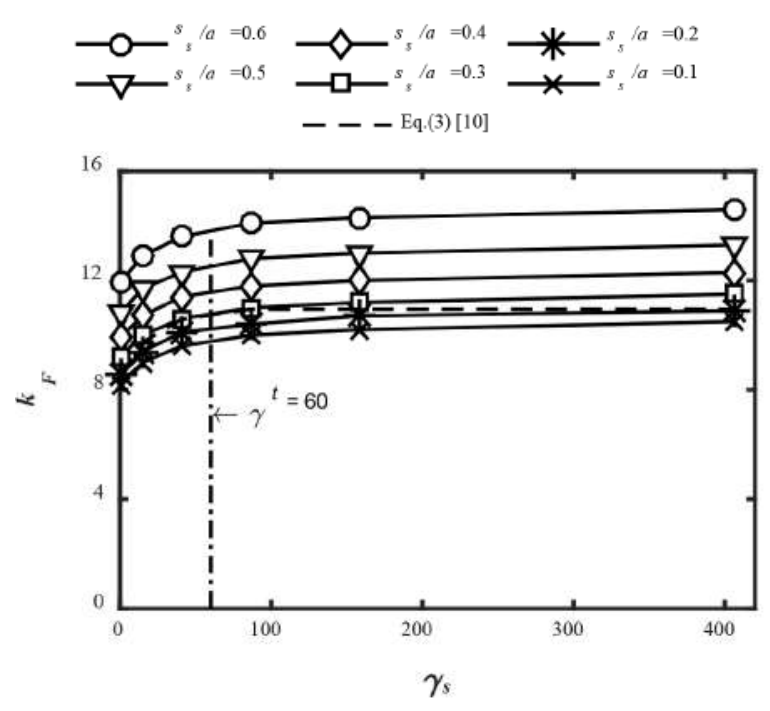

(a) $b_{1} / h_{w}=0.1$

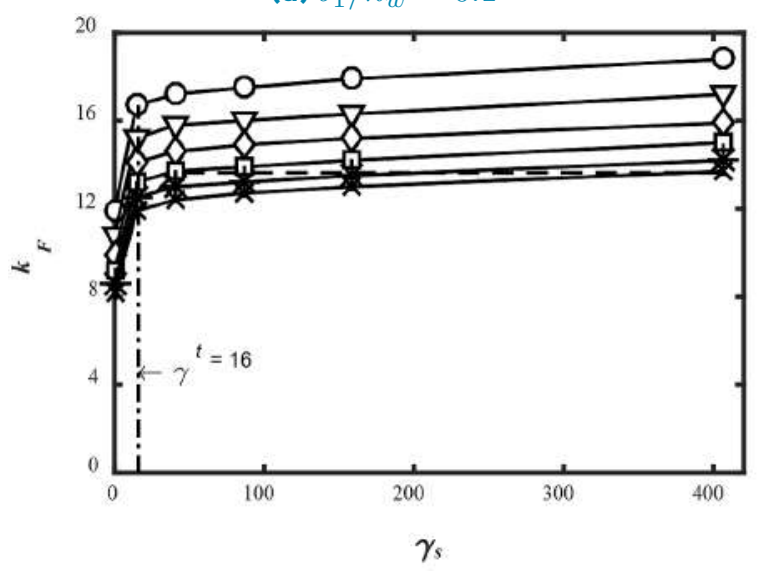

(b) $b_{1} / h_{w}=0.2$

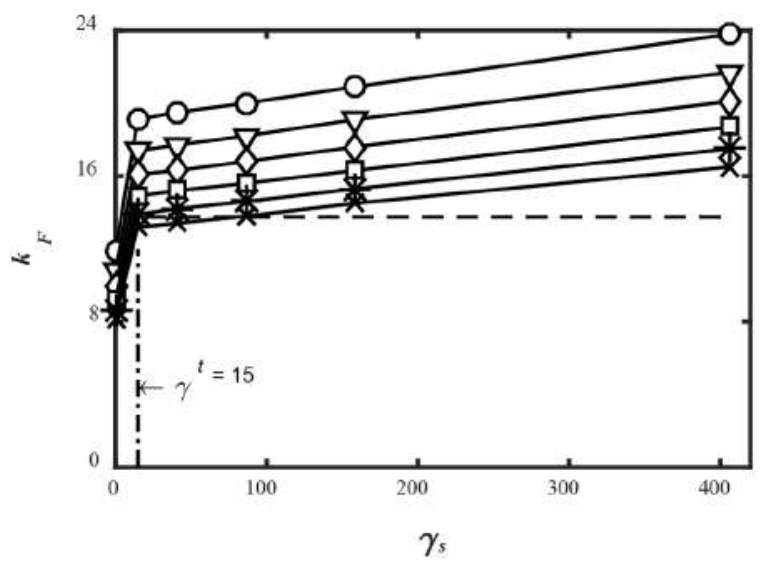

(c) $b_{1} / h_{w}=0.3$

Figure 4 Buckling coefficient $k_{F}$ versus the flexural rigidity of the stiffener $\gamma_{s}\left(a / h_{w}=1\right)$

It is worth noticing that for small panel aspect ratio $\left(a / h_{w}=1\right)$ and a relative position $b_{1} / h_{w} \leq 0.2, k_{F}$ values obtained with Equation (3), and based on the 


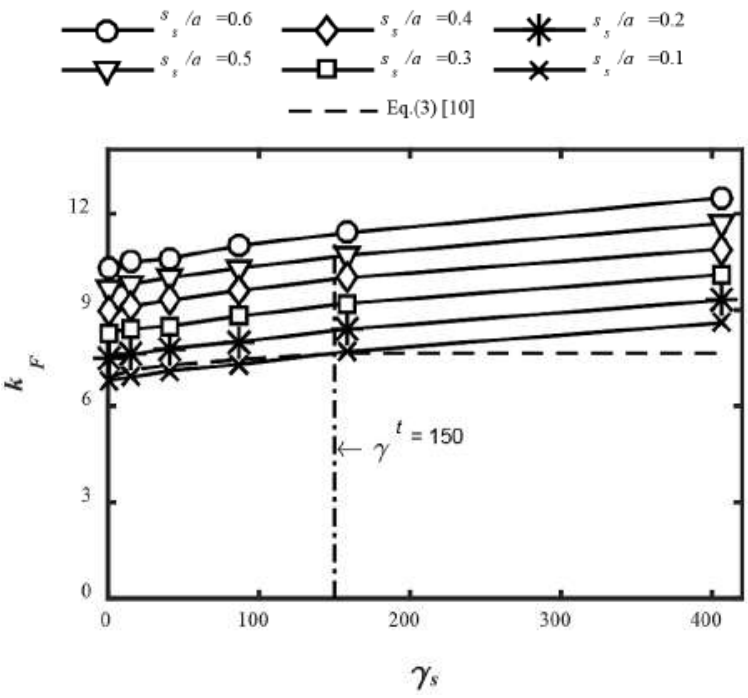

(a) $b_{1} / h_{w}=0.1$

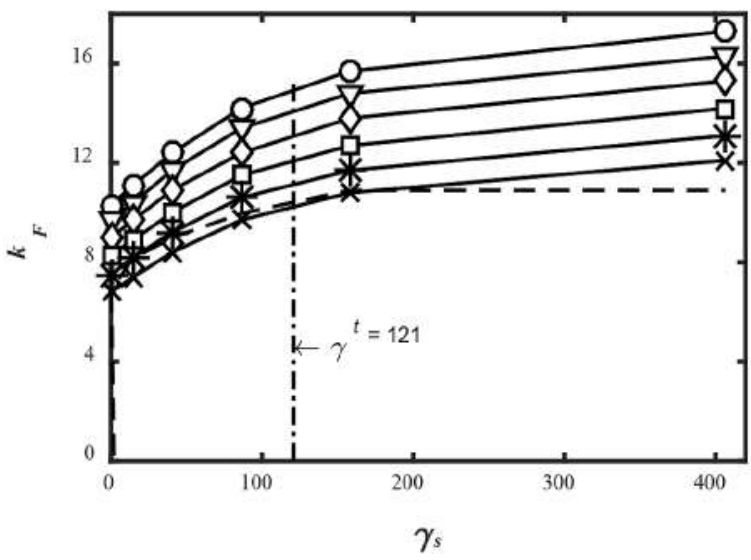

(b) $b_{1} / h_{w}=0.2$

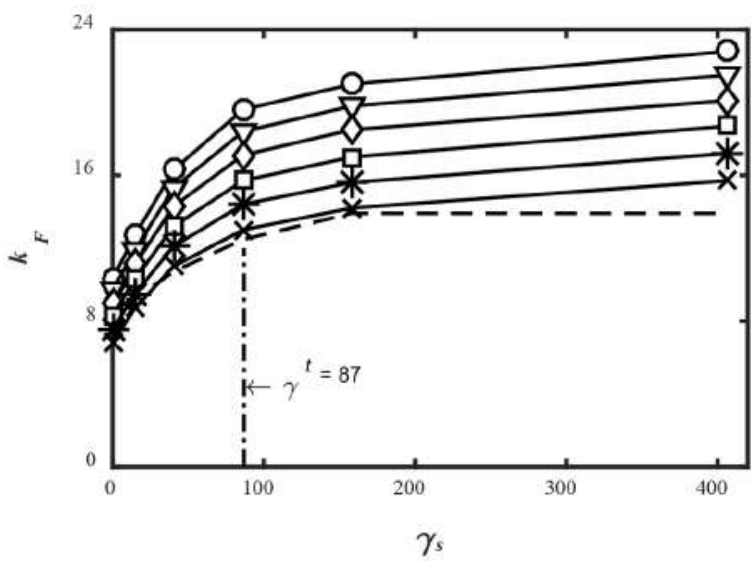

(c) $b_{1} / h_{w}=0.3$

Figure 5 Buckling coefficient $k_{F}$ versus the flexural rigidity of the stiffener $\gamma_{s}\left(a / h_{w}=2\right)$
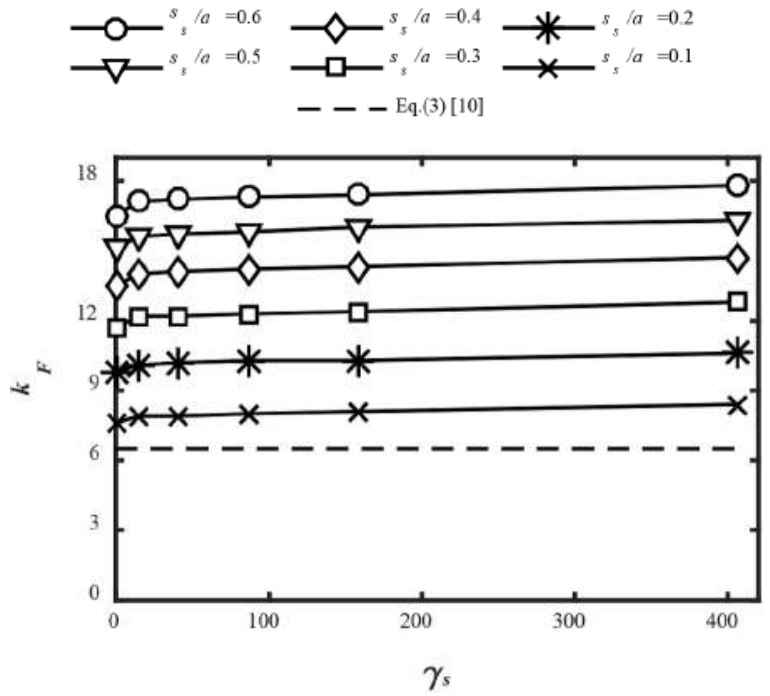

(a) $b_{1} / h_{w}=0.1$

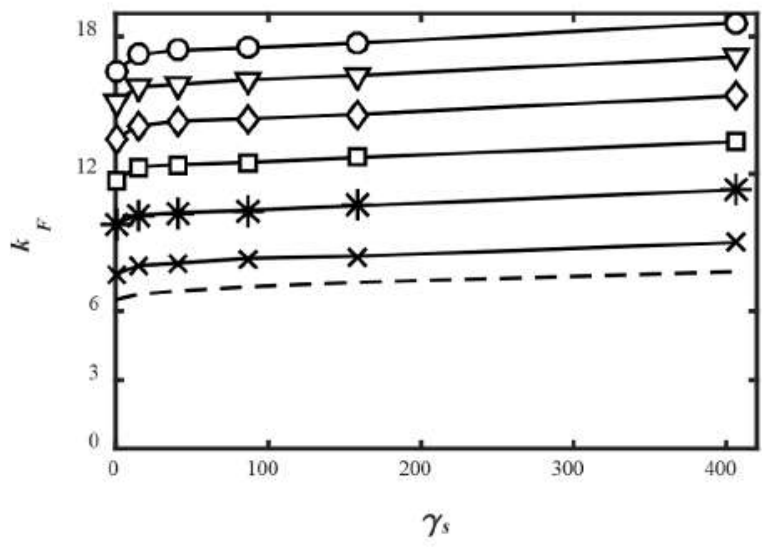

(b) $b_{1} / h_{w}=0.2$

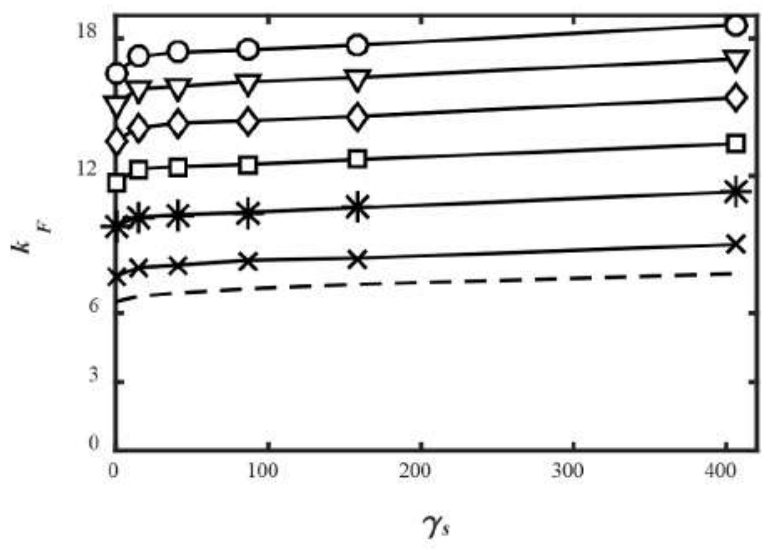

(c) $b_{1} / h_{w}=0.3$

Figure 6 Buckling coefficient $k_{F}$ versus the flexural rigidity of the stiffener $\gamma_{s}\left(a / h_{w}=4\right)$ relative flexural rigidity restriction given in Equation (5), show a close agreement with numerical values for small patch loading length (from $s_{s} / a=0.1$ to 0.2 ). However, for medium or large panel aspect ratios $\left(a / h_{w}=2\right.$ and 4) the buckling coefficients obtained with Equation (3) are lower compared to those computed numerically herein. 
Table 2 Transition rigidities $\gamma^{t}$

In addition to the influence of the position of the stiffener, the variation of the buckling coefficient is also related to the load length $s_{s}$ Figure 7 displays values of $k_{F}$ in terms of $s_{s} / a$ for various relative flexural rigidities $\gamma_{s}=14.8,80.6$ and 158.1 at which the influence of the aspect ratio is also studied. For the $a / h_{w}=1$ (see Figures 7a to $7 \mathrm{c}$ ) there is a nonlinear increment of buckling coefficients as $s_{s} / a$ is increased, while for the other cases $a / h_{w}=2$ and $a / h_{w}=$ 4 the increment is rather linear (Figures $7 d$ to $7 i$ ).

At the same time, another noticeable effect is present when the aspect ratio is $a / h_{w}=4$, Figures $7 \mathrm{~g}$ to $7 \mathrm{i}$ show that for any particular value of $s_{s} / a$, there is no influence of the relative position of the longitudinal stiffener on the buckling coefficient (these elements experience global bucklingl.

\subsection{Transition rigidities}

As mentioned above, transition rigidities $\gamma^{t}$ provide a limit in the $k_{F}$ versus $\gamma_{s}$ curves. The values of the transition rigidities are calculated by intersecting two straight lines obtained through linear regression. A first straight line that captures the rapid increases of $k_{F}$ with respect to $\gamma_{s}$ and a second one that describe the slightly increase of $k_{F}$ vs. $\gamma_{s}$. With, $\gamma^{t}$ determined as the intersection point of the two straight lines. Table 2 shows the results of transition rigidity $\gamma^{t}$ for each calculation; these values remain constant for a patch loading length $s_{s} / a$. For panel aspect ratios $a / h_{w}=1$ and $a / h_{w}=2$ the transition rigidity $\gamma^{t}$ decreases for an increasing stiffener position $b_{1} / h_{w}$. This means that according to the position, the transition rigidity of the stiffener varies. In both cases, the variation of $\gamma^{t}$ with $b_{1} / h_{w}$ follows a different trend. For $a / h_{w}=1$ the results can be compared with those found in [10] where the reduction of $\gamma^{t}$ tends to decrease to a value equal to $\gamma^{t}=15$ for a relative position of $b_{1} / h_{w}=0.3$. In the case of $a / h_{w}=2$ the transition rigidity decrease linearly, nevertheless a difference of $37 \%$ with the Equation 5 is found when the stiffener is placed at $b_{1} / h_{w}=0.3$. On the other hand, for $a / h_{w}=4$ the results are similar to those obtained in [10], where the transition rigidity $\gamma^{t}$ is higher than the relative flexural rigidity $\gamma_{s}$ within the evaluated range.

\subsection{Buckling shapes}

For the sake of visual inspection, Figures 8 to Figure 10 display isometric views of the buckled shapes for three selected conditions for each case $l a / h_{w}=1,2$ and 4, respectively). Three buckled shapes were obtained for a stiffener placed at $b_{1} / h_{w}=0.2$, with $\gamma_{s}=158$. 1 . For panel aspect ratios $a / h_{w}=1$ and 2 , this rigidity is larger than the corresponding transition rigidity $\left(\gamma_{s}>\gamma^{t}\right)$. A closer

\begin{tabular}{|c|c|c|c|c|c|c|c|}
\hline \multirow{2}{*}{$a / h_{w}$} & \multirow{2}{*}{$b_{1} / h_{w}$} & \multicolumn{5}{|c|}{$s_{s} / a$} & \multirow{2}{*}{$\begin{array}{c}\gamma^{t} \\
{[10]}\end{array}$} \\
\hline & & 0.1 & 0.2 & $\begin{array}{ll}0.3 & 0.4\end{array}$ & 0.5 & 0.6 & \\
\hline \multirow[t]{3}{*}{1} & 0.1 & \multicolumn{5}{|c|}{60} & 56 \\
\hline & 0.2 & \multicolumn{5}{|c|}{16} & 35 \\
\hline & 0.3 & \multicolumn{5}{|c|}{15} & 14 \\
\hline \multirow[t]{3}{*}{2} & 0.1 & \multicolumn{5}{|c|}{150} & 157 \\
\hline & 0.2 & \multicolumn{5}{|c|}{121} & 147 \\
\hline & 0.3 & \multicolumn{5}{|c|}{87} & 137 \\
\hline \multirow[t]{3}{*}{4} & 0.1 & \multirow{3}{*}{\multicolumn{5}{|c|}{$>400$}} & \\
\hline & 0.2 & & & & & & $>400$ \\
\hline & 0.3 & & & & & & \\
\hline
\end{tabular}

inspection of the eigenmodes shows a larger wavelength in the lower panel for an increasing load length ratio $s_{s} / a$. All cases show an eigenmode that involves buckling in the lower sub-panel.

Noticeably, as shown in Figures 8 to 10, the buckling shapes are affected by the panel aspect ratio. The buckled region tends to be greater for a larger load length as well as for a wider panel. Moreover, for large panel aspect ratios $a / h_{w}=4$ (see Figure $10 \mathrm{c}$ ), there is an overall buckling mode of the web panel, in which web and longitudinal stiffener buckle together.

Summarizing, Figure 11 shows the buckling modes for the values of $a / h_{w}$ and $s_{s} / a$ analyzed herein. All modes are extracted in the form of the cross-sectional eigenmode at mid-span. It can be observed that the buckling mode in the center of the girder varies only with the aspect ratio instead of the load length. This variation can be observed when the aspect ratio increases as well as the deformation of the web panel. It is worth noticing that for a panel with $a / h_{w}=4$, the longitudinal stiffeners do not provide a stiff nodal line.

\section{Conclusions}

The influence of the bearing length on the critical buckling load of girders subjected to patch loading has been analyzed numerically with a broad perspective herein. The effect of $s_{s} / a$ coupled with many other parameters such as the aspect ratio of the panel, the position, and second moment of area of the stiffeners show the following conclusions:

- Generally, the critical buckling load of the plates increase with $s_{s} / a$. The effect is particularly observable in stiffened plates with low aspect ratio $a / h_{w}=1$ in which the eigenmode is clearly associated with failure of the bottom panel of the directly loaded plate. In these cases, increasing $s_{s} / a$ implies a considerable increment of the buckling coefficient following a nonlinear trend. 

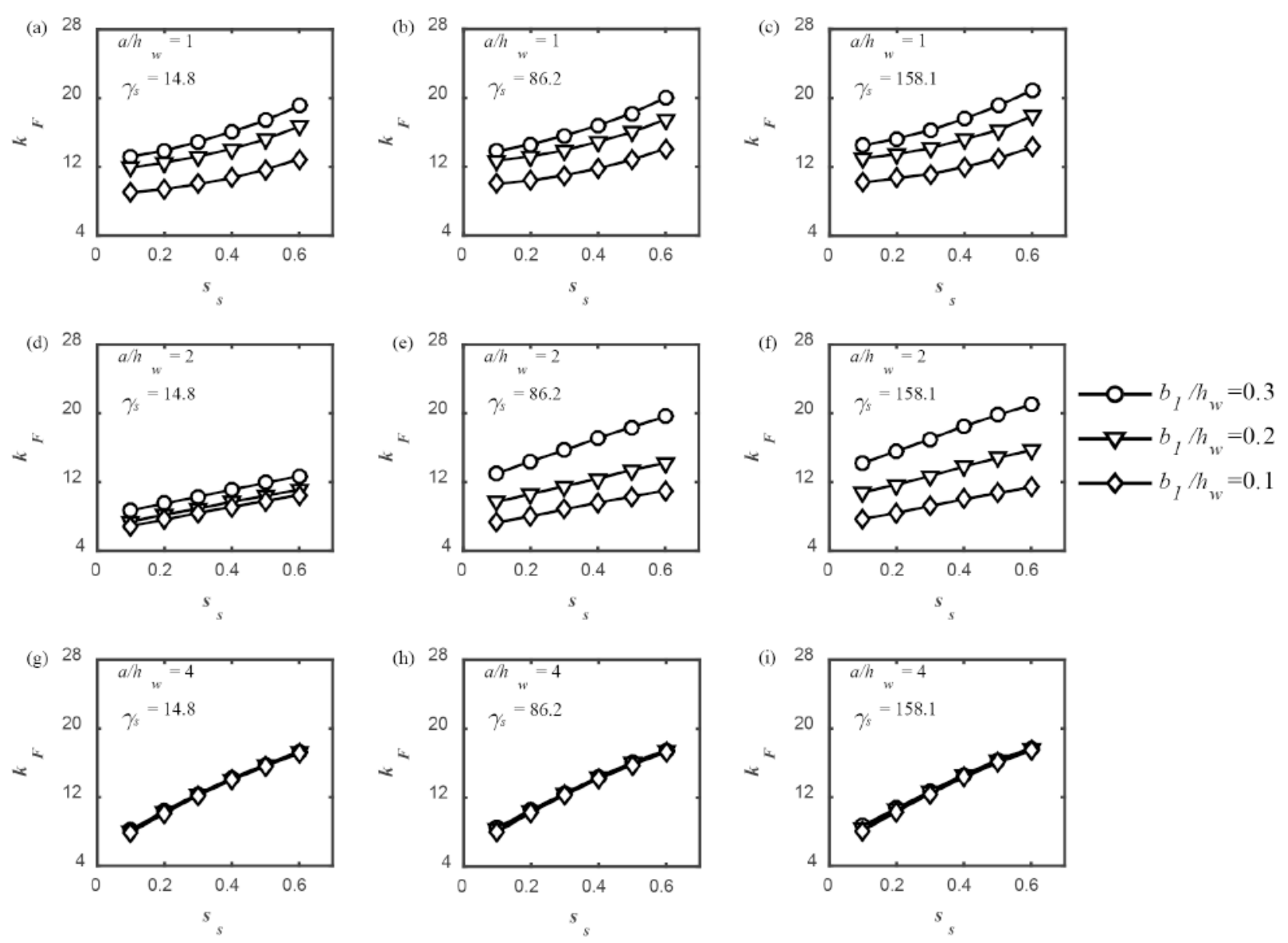

Figure 7 Buckling coefficient $k_{F}$ versus the load length-to width ratio $s_{s} / a$

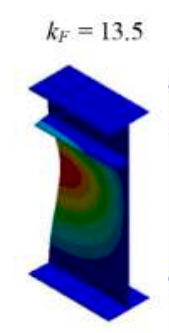

(a) $s_{s} / a=$

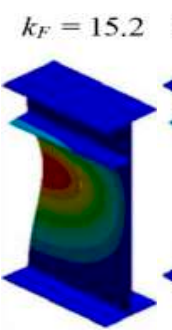

(b) $s_{s} / a=$

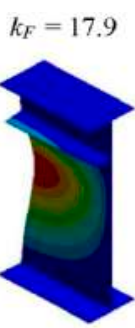

(c) $s_{s} / a=$

0.6

Figure 8 Buckling shapes for plate girders with various loading lengths $\left(a / h_{w}=1 ; b_{1} / h_{w}=0.2 ; \beta=2 ; y_{s}=158.1\right)$

- For stiffened girders with $a / h_{w}=4$, the influence of $s_{s} / a$ is similar lincreasing the buckling coefficient with the loading length) but in this case, the enhancement is smaller. Since the panels are considerably wide, the eigenmode partially involves the longitudinal stiffener and the transverse stiffeners do not contribute to the anchorage of such elements.

These conclusions are necessary to point out when it

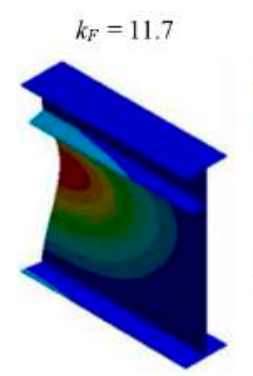

(a) $s_{s} / a=0.2$

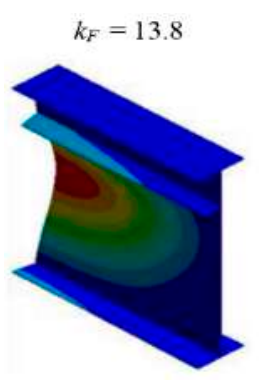

(b) $s_{s} / a=0.4$

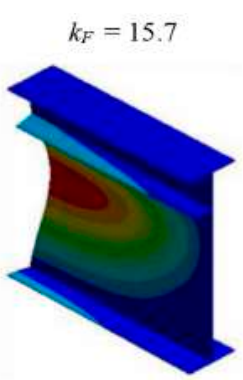

(c) $s_{s} / a=0.6$
Figure 9 Buckling shapes for plate girders with various loading lengths $\left(a / h_{w}=2 ; b_{1} / h_{w}=0.2 ; \beta=2 ; \gamma_{s}=158.1\right)$

comes to the design of plate girders subjected to patch loading. These elements are often designed with largely spaced transverse stiffeners and less frequently with closely spaced stiffeners. Since the launching shoes generally present standard dimensions available in the industry (1.0 to 2.0 meters), the proportion $s_{s} / a$ will be determined by the binomial decision of the transverse stiffener spacing and the utilized launching equipment. 


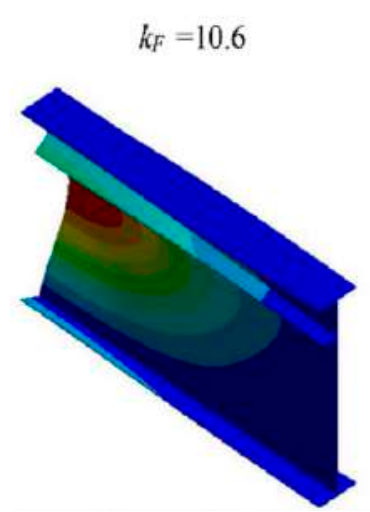

(a) $s_{s} / a=0.2$

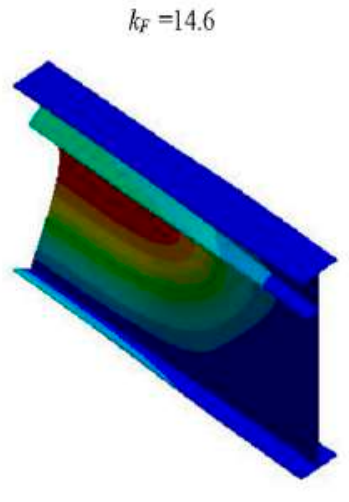

(b) $s_{s} / a=0.4$

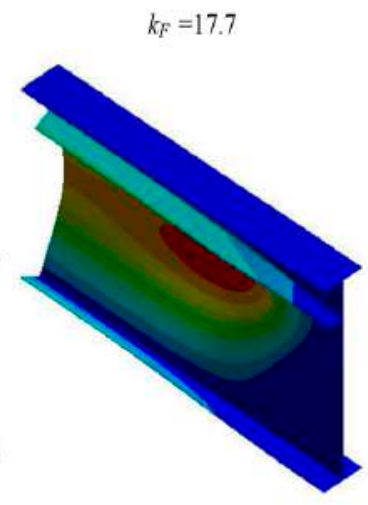

(c) $s_{s} / a=0.6$

Figure 10 Buckling shapes for plate girders with various loading lengths $\left(a / h_{w}=4 ; b_{1} / h_{w}=0.2 ; \beta=2 ; y_{s}=158.1\right)$

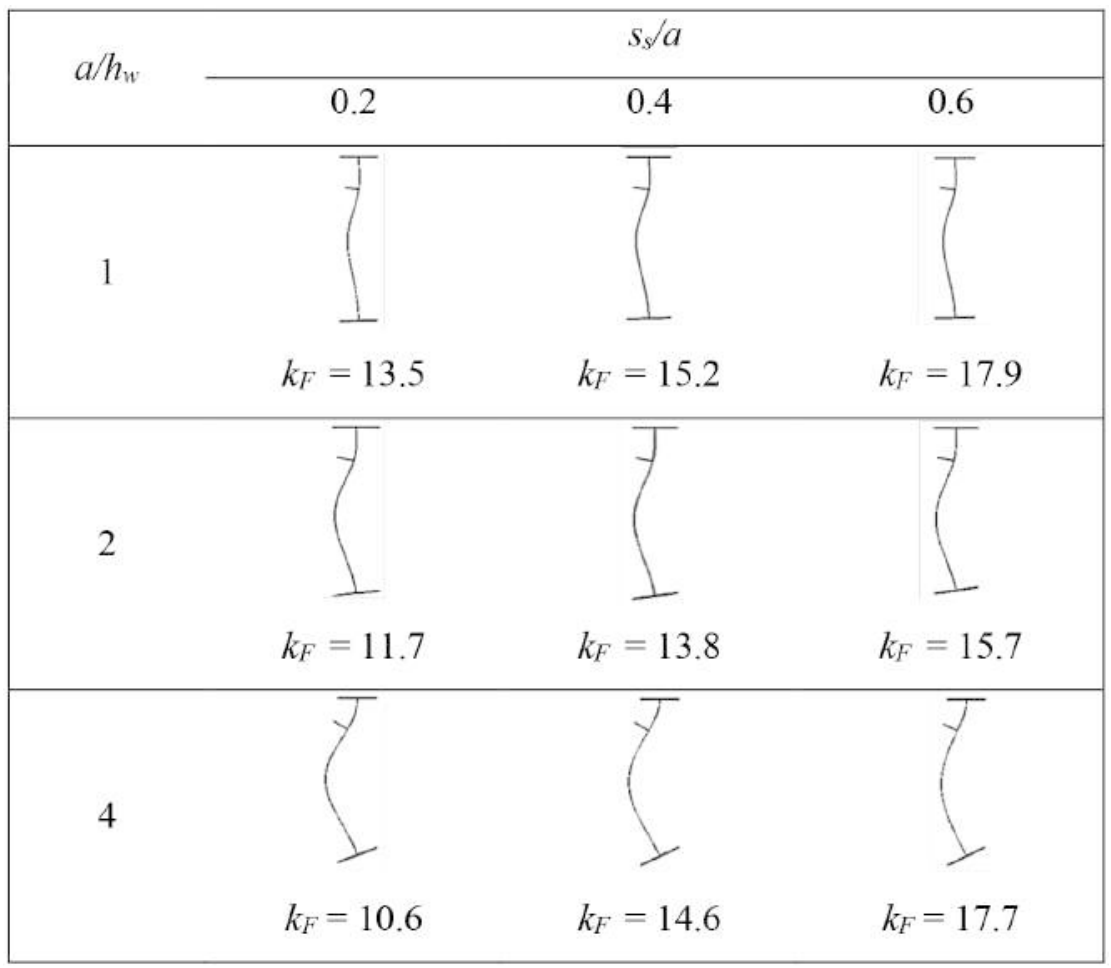

Figure 11 Buckling mode for a plate girder with patch loading lengths $\left(b_{1} / h_{\mathrm{w}}=0.2 ; \beta=2 ; \gamma_{s}=158.1\right)$

The resistance of webs to concentrated loads will benefit in the case of closely spaced transverse stiffeners and/or large launching shoes since coupled mechanisms involving the transverse and longitudinal reinforcements will determine the load bearing capacity of the plate girder as whole. Finally, it is recommended to study these complex coupled resistant mechanisms not only from the critical buckling load perspective but also at ultimate load capacity levels.

\section{References}

[1] Eurocode 3: Design of steel structures, Part 1-5: General rules, supplementary rules for planar plated structures without transverse loading, ENV 1993-1-5, 2006.

[2] Specification for Structural Steel Buildings, ANSI/AISC 360-16 An American National Standard, 2016.

[3] K. C. Rockey and D. K. Bagchi, "Buckling of plate girder webs under partial edge loading," International Journal of Mechanical Sciences, vol. 12, no. 1, pp. 61-76, Jan. 1970.

[4] C. K. Chin, F. G. A. Al-Bermani, and S. Kitipornchai, "Finite element method for buckling analysis of plate structures," J. Struct. Eng., vol. 119, no. 4, pp. 1048-68, Apr. 1993.

[5] F. Shahabian and T. M. Roberts, "Buckling of slender web plates 
subjected to combination of in-plane loading," J. Constr. Steel. Res. vol. 51, no. 2, pp. 99-121, Aug. 1999.

[6] K. C. Rockey, A. Samuelsson, and H. Wennerström, "The buckling of longitudinally reinforced web plates loaded by a central in-plane patch load," in Stability Problems Engineering Structures and components. London, England: Applied Science Publishers, 1979, pp. 75-88.

[7] T. R. Graves and J. T. Gierlinski, "Buckling of stiffened webs by local edge loads," J. Struct. Div-Asce, vol. 108, no. 6, pp. 1357-1366, 1982.

[8] V. Kristek and M. Skaloud, Advanced Analysis and Design of Plated Structures. Prague, Czechoslovakia: Elsevier Science Ltd, 1991.

[9] O. Lagerqvist, "Patch loading : resistance of steel girders subjected to concentrated forces," Ph.D. dissertation, Luleå University of Technology, Structural and Construction Engineering, 1995.

[10] C. Graciano and O. Lagerqvist, "Critical buckling of longitudinally stiffened webs subjected to compressive edge loads," Journal of Constructional Steel Research, vol. 59, no. 9, pp. 1119-1146, Sep. 2003.

[11] T. Ren and G. S. Tong, "Elastic buckling of web plates in i-girders under patch and wheel loading," Engineering Structures, vol. 27, no. 10, pp. 1528-1536, Aug. 2005.

[12] E. Maiorana, C. Pellegrino, and C. Modena, "Linear buckling analysis of unstiffened plates subjected to both patch load and bending moment," Engineering Structures, vol. 30, no. 2, pp. 3731-3738, Dec. 2008.

[13] O. Mezghanni, J. Averseng, A. Bouchaïr, and H. Smaoui, "Behavior of beam web panel under opposite patch loading," J. Constr. Steel. Res., vol. 83, pp. 51-61, Apr. 2013.

[14] C. Graciano and J. Mendes, "Elastic buckling of longitudinally stiffened patch loaded plate girders using factorial design," J. Constr. Steel. Res., vol. 100, pp. 229-236, Sep. 2014.

[15] C. Graciano, "Patch loading resistance of longitudinally stiffened girders-a systematic review," Thin-Wall Struct., vol. 95, pp. 1-6, Oct. 2015.

[16] C. D. Tetougueni, E. Maiorana, P. Zampieri, and C. Pellegrino, "Plate girders behaviour under in-plane loading: A review," Eng. Fail. Anal., vol. 95, pp. 332-358, Jan. 2019.
[17] Q. A. Hasan, W. H. W. Badaruzzaman, A. W. Al-Zand, and A. A. Mutalib, "The state of the art of steel and steel concrete composite straight plate girder bridges," Thin-Wall Struct., vol. 119, pp. 988-1020, Oct. 2017.

[18] S. Shimizu, "The collapse behaviour of web plates on the launching shoe," Journal of Constructional Steel Research, vol. 31, no. 1, pp. $59-72,1994$

[19] R. Chacón, E. Mirambell, and E. Real, "Transversally stiffened plate girders subjected to patch loading: Part 2. additional numerical study and design proposal," Journal of Constructional Steel Research, vol. 80, pp. 492-504, 2013.

[20] R. Chacón, "Mechanical behavior of the shear-patch loading interaction on transversally stiffened steel plate girders," Lat. Am. J. Solids Stru., vol. 11, no. 10, pp. 1721-1743, 2014.

[21] N. Loaiza, C. Graciano, R. Chacón, and E. Casanova, “Influence of bearing length on the patch loading resistance of multiple longitudinally stiffened webs," ce/papers, vol. 1, no. 2-3, pp. 4199-4204, 2017.

[22] N. Loaiza, C. Graciano, and E. Casanova, "Design recommendations for patch loading resistance of longitudinally stiffened i-girders," Engineering Structures, vol. 171, pp. 747-758, 2018.

[23] B. Kövesdi, B. Mecséri, and L. Dunai, "Imperfection analysis on the patch loading resistance of girders with open section longitudinal stiffeners," Thin-Walled Structures, vol. 123, pp. 195-205, 2018.

[24] N. Markovic and S. Kovacevic, "Influence of patch load length on plate girders. part i: Experimental research," Journal of Constructional Steel Research, vol. 157, pp. 207-228, 2019.

[25] S. P. Timoshenko, Theory of elastic stability, 2nd ed. McGraw-Hill Book Company, 1961.

[26] F. Bleich, Buckling Strength of Metal Structures, 1st ed. McGraw-Hill Book Company, 1952.

[27] T. H. G. Megson, Introduction to Aircraft Structural Analysis. Butterworth-Heinemann, 2010.

[28] ANSYS Release 19.0 Elements Reference, ANSYS, Inc., USA, 2018.

[29] M. Clarin, "Plate buckling resistance patch loading of longitudinally stiffened webs and local buckling," PhD Thesis, Luleå University of Technology, Escandinavia, Suecia, 2007. 